\title{
Erratum
}

\section{Chiral Sodium Phosphate Catalyzed Enantioselective 1,4-Addition of TMSCN} to Aromatic Enones

Jingya Yang, Shaoxiang Wu, Fu-Xue Chen* Synlett 2010, 2725.

In Scheme 1 the structures of compounds $6 \mathbf{h}$ and $\mathbf{7 h}$ were misassigned. The correct structures are redrawn correctly in the following Scheme. The authors apologize for this error.<smiles>Oc1ccc2cc(C3CC4CCC3C4)ccc2c1-c1c(O)ccc2cc(C3CC4CCC3C4)ccc12</smiles>

$6 \mathrm{~h}$
1) $\mathrm{POCl}_{3}$, pyridine, r.t. 2) $\mathrm{H}_{2} \mathrm{O}$, r.t. $90 \%$

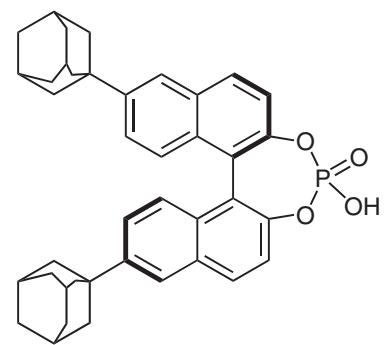

$7 \mathrm{~h}$

Scheme 1 